\title{
PERTUMBUHAN Rhizophora stylosa PADA TAMBAK SILVOFISHERY DI DESA TANJUNG REJO KECAMATAN PERCUT SEI TUAN KABUPATEN DELI SERDANG
}

\author{
Delvian, Ridahati Rambe dan Edy Batara Mulya Siregar \\ Fakultas Kehutanan Universitas Sumatera Utara \\ Jalan Tri Dharma Ujung Kampus USU Medan \\ e-mail : delvian@usu.ac.id
}

\begin{abstract}
Abstrak
Ekosistem hutan mangrove mempunyai manfaat ekonomi dan ekologi yang sangat besar namun keberadaannya terancam dengan kegiatan pembangunan tambak yang terus bertambah. Pengembangan tambak dengan sistem silvofishery diharapkan dapat mempertahankan fungsi ekologi hutan mangrove tanpa mengabaikan kepentingan ekonomi bagi masyarakat di wilayah pesisir. Kegiatan ini bertujuan untuk mengetahui pertumbuhan R. stylosa yang ditanam pada lahan tambak milik masyarakat. Lahan tambak digunakan untuk budidaya kepiting dan ikan nila. Variabel amatan berupa pertambahan tinggi dan diameter tanaman R. stylosa pada kedua lahan tambak tersebut. Hasil pengukuran menunjukkan bahwa pertambahan tinggi dan diameter $\mathrm{R}$. stylosa pada lahan tambak kepiting lebih baik dibandingkan dengan lahan tambak ikan nila.
\end{abstract}

Kata kunci: silvofishery, $R$. stylosa, tinggi tanaman, diameter batang

\section{PENDAHULUAN}

Ekosistem hutan bakau bersifat khas, baik karena adanya pelumpuran yang mengakibatkan kurangnya aerasi tanah, salinitas tanahnya yang tinggi, serta mengalami daur penggenangan oleh pasangsurut air laut. Hanya sedikit jenis tumbuhan yang bertahan hidup di tempat semacam ini, dan jenis-jenis ini kebanyakan bersifat khas hutan bakau karena telah melewati proses adaptasi dan evolusi.

Di Indonesia, hutan-hutan mangrove yang luas terdapat di seputar Dangkalan Sunda yang relatif tenang dan merupakan tempat bermuara sungai-sungai besar. Yakni di pantai timur Sumatra, dan pantai barat serta selatan Kalimantan. Di pantai utara Jawa, hutan-hutan ini telah lama terkikis oleh kebutuhan penduduknya terhadap lahan.

Berbagai alternatif pengelolaan dapat dilakukan terhadap hutan mangrove yang ada.

Masyarakat lokal misalnya, mereka mengkonversi dan memanfaatkan lahan mangrove sesuai dengan kebutuhan hidup, kemampuan mereka dan pandangan mereka atau persepsi tentang hutan mangrove. Dengan berbagai bentuk pemanfaatan yang ada, menyebabkan terjadinya perbedaan dalam perolehan pendapatan dari usaha mengelola hutan mangrove tersebut.
Pola pemanfaatan yang dilakukan dalam usaha mencukupi kebutuhan hidup sesuai kemampuan yang masyarakat miliki belum tentu benar dengan apa yang seharusnya dilakukan. Hal tersebut dikarenakan masih terdapat aktor aktor yang melakukan kesalahan-kesalahan dalam memanfaatkan ekosistem mangrove, seperti mengeksploitasi lahan hutan mangrove dan mengkonversinya menjadi tambak, pemukiman, lahan pertanian, lahan perkebunan, industri dan/atau lainnya dalam skala besar tanpa memikirkan keberlanjutan ekosistem pesisir itu serdiri. Berbagai aktivitas manusia tersebut menyebabkan penurunan luas hutan mangrove dan berakibat juga pada penurunan fungsi dan manfaat mangrove bagi penduduk dan lingkungan sekitarnya.

Agar rakyat Indonesia tetap mampu menjadikan hutan mangrove sebagai sumber mata pencahariannya, maka perlu pengelolaan secara berkelanjutan. Dasar yang dapat dijadikan pijakan adalah karena pengelolaan SDA hutan mangrove mempunyai tujuan utama untuk menciptakan ekosistem yang produktif dan berkelanjutan untuk menopang berbagai kebutuhan pengelolaannya.

Vaipasha et al. (2007) menyebutkan bahwa fungsi mangrove dalam tambak silvofishery berfungsi sebagai biofilter bagi buangan 
Delvian. et al. Pertumbuhan Rhizophora Stylosa Pada Tambak Silvofishery di Desa Tanjung Rejo ...

tambak. Hal ini bertujuan agar buangan tambak tidak melampaui kemampuan asimilasi lingkungan. Sementara Primavera dan Esteban (2008) menyebutkan bahwa tanaman mangrove berfungsi sebagai peneduh dan penyedia makanan bagi ikan dan udang. Mangrove juga memiliki peranan yang penting sebagai tempat asuhan ikan (Manson et al., 2005). Selnjutnya, disebutkan juga bahwa vegetasi mangrove memberikan perlindungan

dari predator, sumber pakan yang melimpah, dan perlindungan dari gangguan fisik. Dengan demikian, keberadaan ekosistem mangrove perlu dipertahankan untuk menjaga keberlanjutan sumberdaya perikanan di wilayah pesisir.

Dewasa ini, pengelolaan lingkungan secara terpadu disinyalir terbukti memberikan peluang pengelolaan yang cukup efektif dalam rangka menyeimbangkan antara pelestarian lingkungan dan pemanfaatan ekonomi. Salah satu metode rehabilitasi yang memungkinkan peran aktif masyarakat adalah penerapan teknologi silvofishery atau silvofishery. Silvofishery adalah sistem pertambakan teknologi tradisional yang menggabungkan antara usaha perikanan dengan penanaman mangrove, yang diikuti konsep pengenalan sistem pengelolaan dengan meminimalkan input dan mengurangi dampak terhadap lingkungan (Macintosh et al, 2002 dalam Shilman, 2012). Program silvofishery tersebut merupakan suatau upaya peningkatan produktivitas tambak dengan menanamkan mangrove pada tambak selain itu upaya penanaman mangrove pada tambak tersebut juga dimaksudkan sebagai upaya antisipasi terhadap bahaya abrasi yang mengancam lahan tambak. Dengan penerapan sistem silvofishery ini konflik antara kebutuhan lahan untuk aktivitas perekonomian masyarakat dan juga untuk ketahanan lingkungan dapat berjalan beriringan dan saling menguatkan.

\section{BAHAN DAN METODA}

\section{A. Lokasi dan Waktu}

Kegiatan ini dilakukan pada tambak silvofishery milik masyarakat di Tanjung Rejo, Kecamatan Percut Sei Tuan, Kabupaten Deli Serdang Sumatera Utara. Waktu Pelaksanaan kegiatan adalah Agustus Desember 2016.

\section{B. Alat dan Bahan}

Jenis tanamannya adalah Rhizophora stylosa sedangkan jenis hewan tambak yang digunakan dalam kegiatan ini adalah kepiting dan ikan nila (Oreochromis niloticus). Ukuran tambak kepiting adalah 3,2 ha sedangkan tambak udang dengan ukuran 4,6 ha.

Peralatan penelitian adalah timbangan digital, tali tambang, caliper digital, meteran, kamera untuk mendokumentasikan kegiatan dan obyek penelitian, buku lapangan serta alat tulis menulis.

\section{Metode Penelitian}

Kegiatan yang dilakukan berupa pengamatan dan pengukuran pertumbuhan mangrove. Pengukuran pertumbuhan mangrove pada tambak silvofishery merupakan salah satu cara yang dilakukan untuk mengetahui perkembangan tanaman pada setiap periode pengamatan. Parameter yang diamati adalah diameter, tinggi tanaman serta jumlah akar. Data dianalisis secara kuantitatif dengan menghitung penambahan setiap parameter pengamatan, selanjutnya dibahas secara deskriptif untuk melihat dinamika tegakan pada masing-masing plot silvofishery.

\section{HASIL DAN PEMBAHASAN}

Kegiatan penanaman propagul rhizophora dilakukan pada bulan September. Pengamatan pertumbuhan rhizophora dilakukan selama bulan Oktober - Desember 2016 dengan interval waktu pengamatan empat minggu. Variabel pengamatan berupa pertambahan tinggi tanaman dan diameter batang. Hasil pengamatan pertambahan tinggi dan diameter rhizophora disajikan pada Tabel 1 dan Gambar 1.

Tabel 1. Rata-rata pertambahan tinggi $R$. stylosa selama tiga bulan pengukuran 
Delvian. et al. Pertumbuhan Rhizophora Stylosa Pada Tambak Silvofishery di Desa Tanjung Rejo ...

\begin{tabular}{|l|c|c|c|c|c|}
\hline \multirow{2}{*}{ Jenis Tambak } & \multirow{2}{*}{$\begin{array}{c}\text { Tanaman } \\
\text { Sampel }\end{array}$} & \multicolumn{3}{|c|}{$\begin{array}{c}\text { Rata-ratap pertambahan } \\
\text { tinggi tanaman }(\mathrm{cm})\end{array}$} & \multirow{2}{*}{ Rata-rata } \\
\cline { 3 - 5 } & & Oktober & November & Desember & \\
\hline Ikan Nila & 50 & 1,61 & 3,89 & 5,69 & 3,73 \\
\hline Kepiting & 50 & 2,43 & 4,73 & 7,08 & 4,75 \\
\hline
\end{tabular}

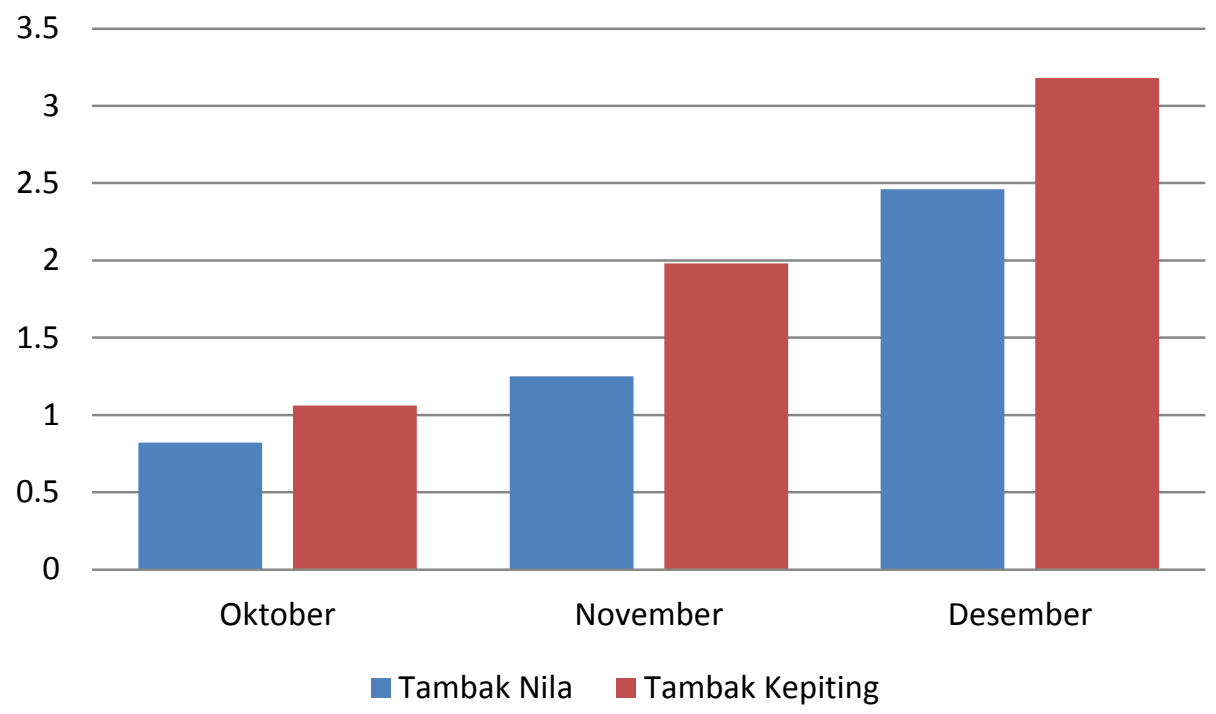

Gambar 1. Laju pertambahan tinggi (cm) R. stylosa pada dua lahan tambak

Berdasarkan Tabel 1 diketahui bahwa pertumbuhan $R$. Stylosa pada tambak kepiting menunjukkan rata-rata pertumbuhan tertinggi dibanding tambak ikan nila dalam tiga kali pengamatan. Hal ini diduga karena lokasi tambak kepiting ada pada saluran utama saluran pasang surut sehingga pertukaran air tambak berjalan lebih baik. Sementara itu lokasi tambak ikan nila berada cukup jauh dari saluran utama. Kondisi kesuburan tanah pada kedua lokasi diduga juga mempengaruhi pertumbuhan $R$. stylosa terutama dalam hal kandungan bahan organik pada lahan tambak. Masalah perbedaan kesuburan tanah ini belum dapat dibahas secara mendalam karena sampai artikel ini disiapkan hasil analisis kesuburan tanah kedua lahan tambak belum diperoleh.

Sama halnya dengan pertambahan tinggi tanaman, pertambahan diameter juga mempunyai pola yang sama dimana pertambahan diameter batang R. stylosa pada tambak kepiting lebih besar daripada di tambak ikan nila. Kondisi ini diduga juga berhubungan dengan lokasi letak tambak dan tingkat kesuburan lahan tambak. Pertambahan diameter R. stylosa pada kedua tambak disajikan pada Tabel 2 dan Gambar 2.

Tabel 2. Rata-rata pertambahan diameter $R$. stylosa selama tiga bulan pengukuran

\begin{tabular}{|l|c|c|c|c|c|}
\hline \multirow{2}{*}{ Jenis Tambak } & \multirow{2}{*}{$\begin{array}{c}\text { Tanaman } \\
\text { Sampel }\end{array}$} & \multicolumn{3}{|c|}{$\begin{array}{c}\text { Rata-ratap pertambahan } \\
\text { diameter tanaman }(\mathrm{cm})\end{array}$} & \multirow{2}{*}{ Rata-rata } \\
\cline { 3 - 5 } & & Oktober & November & Desember & \\
\hline Ikan Nila & 50 & 0,82 & 1,25 & 2,46 & 1,51 \\
\hline Kepiting & 50 & 1,06 & 1,98 & 3,18 & 2,07 \\
\hline
\end{tabular}


Delvian. et al. Pertumbuhan Rhizophora Stylosa Pada Tambak Silvofishery di Desa Tanjung Rejo ...

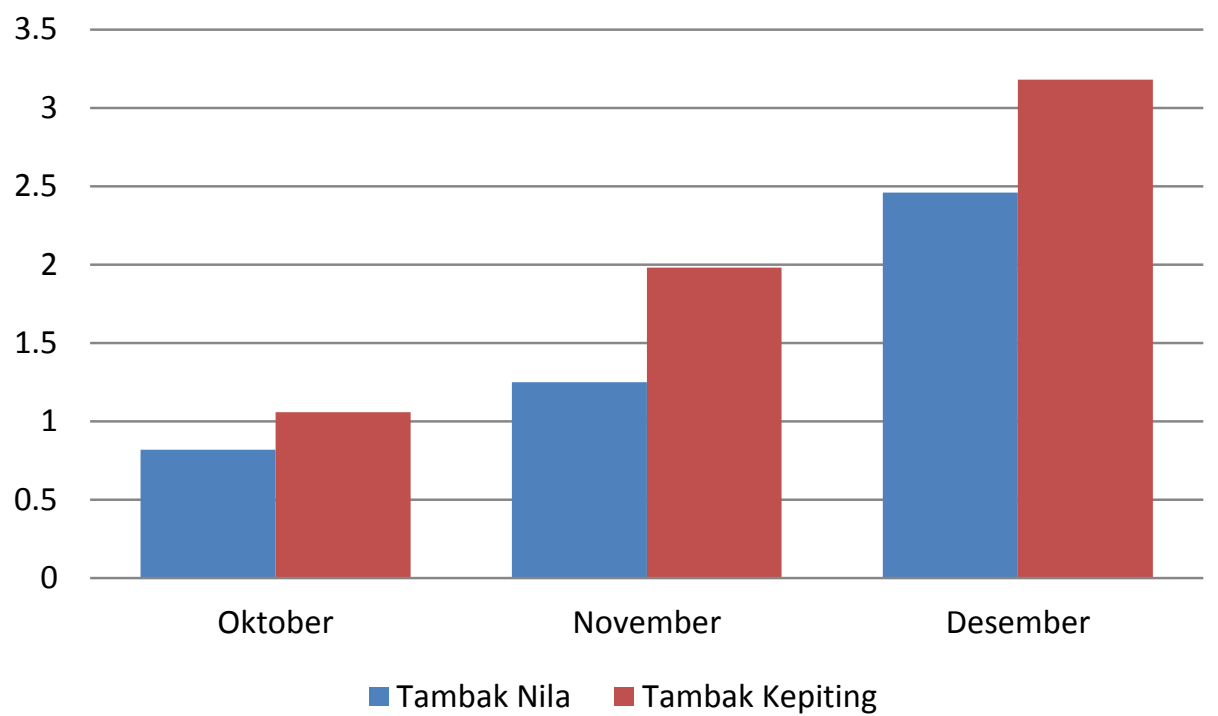

Gambar 2. Laju pertambahan diameter (cm) R. stylosa pada dua lahan tambak

Perkembangan tanaman pada masing-masing plot dapat berbeda sesuai dengan daya dukung lingkungan dan pola adaptasinya. Pertumbuhan tanaman mangrove pada masing-masing plot dalam dalam tiap periode pengukuran disajikan

pada Gambar 1. Secara umum pertumbuhan tinggi pada plot penelitian mengikuti kurva normal kecuali pada plot D.

Menurut Kathiseran dan Bingham (2001) bahwa Rhizopora sp. merupakan jenis yang masuk dalam zona proksimal yaitu kawasan (zona) yang terdekat dengan laut. Pada umumnya jenis ini terletak di belakang zona Avicennia sp. dan Sonneratia sp. Dengan kadar garam yang lebih rendah perakaran jenis Rhizophora sp. pada umumnya hanya terendam pada saat air pasang berlangsung. Idealnya untuk kegiatan silvofishery tersebut perlu dibuatkan guludan sebagai area penanaman khusus di dalam tambak. Guludan tersebut dikondisikan agar tanaman tidak selalu tergenang di mana tanaman hanya akan terendam pada saat terjadinya air pasang, sedangkan pada saat air surut tanaman tidak terendam air. Sementara itu untuk current area atau area pemeliharaan ikan, dilakukan pada tempat yang lebih rendah sehingga pada saat air surut pun tetap dalam keadaan terendam air.

Budidaya tambak dengan sistem silvofishery telah banyak diterapkan di Indonesia. Peran mangrove sebagai penyedia jasa lingkungan merupakan faktor yang diharapkan mampu mendukung kegiatan budidaya tambak. Jasajasa tersebut meliputi secara fisik, kimia maupun biologi. Peran fisik mangrove bagi lingkungan adalah sebagai pemerangkap sedimen (Pramudji, 2004). Sementara peran kimia mangrove adalah sebagai penyerap bahan pencemar, penyuplai bahan organik dan sumber nutrien (Pramudji, 2002). Sedangkan peran biologis mangrove adalah sebagai area pemijahan (spawning ground), area asuhan (nursery ground) dan area pencarian makan (feeding ground) bagi berbagai biota perairan (Supriharyono, 2009). Poedjirahajoe (2000) membuktikan pengaruh silvofishery terhadap pertumbuhan ikan Bandeng. Dalam uji coba yang dilakukan selama 3 bulan, ikan Bandeng yang dipelihara pada tambak silvofishery mengalami pertumbuhan rata-rata 100 gr lebih tinggi dibandingkan dengan ikan Bandeng yang dipelihara pada tambak biasa. Sementara Mardiyati (2004) menunjukkan bahwa budidaya tambak dengan sistem silvofishery memberikan keuntungan yang lebih tinggi dibandingkan dengan tambak biasa. Penelitian ini bertujuan untuk menkaji pengaruh silvofishery terhadap kondisi lingkungan tambak dan pertumbuhan udang.

Shimoda et al. (2006) menyebutkan bahwa salah satu peran mangrove dalam kegiatan 
Delvian. et al. Pertumbuhan Rhizophora Stylosa Pada Tambak Silvofishery di Desa Tanjung Rejo ...

budidaya tambak adalah sebagai biofilter, meskipun sebenarnya masih ada jenis-jenis biofilter lain yang dapat digunakan. Fungsi biofilter dalam budidaya tambak adalah untuk mengurangi beban pencemar yang akan dibuang ke perairan (sungai atau laut), sehingga kegiatan budidaya yang dilakukan akan lebih berkelanjutan. Primavera (2006) menyebutkan beberapa dampak negatif dari kegiatan budidaya yang dapat timbul antara lain hilangnya tutupan mangrove, hasil tangkap samping pada saat pengumpulan benih, masuknya jenis biota baru, penyebaran parasit dan penyakit, penyalahgunaan bahan kimia dan timbulnya buangan limbah.

Menurut Walters et al. (2008) pengelolaan mangrove diperlukan untuk menjaga kelangsungan pemanfaatan sumberdaya di wilayah pesisir. Di sisi lain, dengan terjaganya ekosistem mangrove di wilayah pesisir, diharapkan kondisi lingkungna wilayah pesisir dapat pulih seperti sedia kala. Dengan demikian kelangsungan pemanfaatan sumberdaya pesisir dapat dipertahankan dan dilestarikan.

\section{KESIMPULAN} daripada lahan tambang ikan nila. Perbedaan pertambahan tinggi dan diameter tanaman ini diduga berhubungan dengan kualitas kesuburan lahan dan periode keluar masuknya air pada areal tambak.

\section{DAFTAR PUSTAKA}

Kathiseran K \& Bingham BL. 2001. Biology of mangroves and mangrove ecosystems. Advances in Marine Biology 40, 81-251.

Manson, F.J., N.R. Loneragan, G.A. Skilleter, S.R. Phinn, 2005, An Evaluation of the Evidence for Linkages Between Mangroves and Fisheries: A Synthesis of the Literature and Identification of Research Directions, Oceanography and Marine Biology: an Annual Review 43: 485 - 515

Mardiyati, S, 2004, Optimasi Usahatani Tumpangsari Empang Parit di Lahan Konservasi Hutan Mangrove RPH Cikiperan BKPH Rawa Timur KPH Banyumas Barat,
Tesis, Program Pasca Sarjana, UGM, Yogyakarta.

Pramudji, 2002, Kajian Hutan Mangrove di Kawasan Pesisir Kabupaten Penajam, Kalimantan Timur, Laporan Penelitian, Pusat Penelitian Oseanogafi LIPI, Jakarta.

Pramudji, 2004, Mangrove di Pesisir Delta Mahakam Kalimantan Timur, Pusat Penelitian Oseanografi LIPI, Jakarta: 3-7.

Primavera, J.H., 2006, Overcoming the Impacts of Aquatculture on the Coastal Zone. Ocean and Coastal Management 49: 531 545

Primavera J. H., J. M. A. Esteban, 2008, A Review of Mangrove Rehabilitation in the Philippines: Successes, Failures and Future Prospects, Wetlands Ecology and Management 16: 345 - 358

Poedjirahajoe, E., 2000, Pengaruh Pola Sylvofishery terhadap Pertambahan Berat Ikan Bandeng (Chanos chanos Forskal) di Kawasan Mangrove Pantai Utara Kabupaten Brebes, Jurnal Konservasi Kehutanan 2: 109124

Shilman, M.I.2012. Kajian Penerapan Silvofishery Untuk Rehabilitasi Ekosistem Mangrove Di Desa Dabong Kecamatan Kubu Kabupaten Kubu Raya Provinsi Kalimntan Barat. diunduh dari repository.ipb.ac.id pada tanggal 10 Desember 2013.

Shimoda, T., E. Suryati, T. Ahmad, 2006, Evaluation in A Shrimp Aquaculture System Using Mangrove, Oyster and Seaweed as Biofilters Based on the Concentrations of Nutrients and Chlorophyll a, JARQ 40(2): $189-193$

Supriharyono, 2009, Konservasi Ekosistem Sumberdaya Hayati, Penerbit Pustaka Pelajar, Yogyakarta.

Vaiphasa, C., W. F. de Boer, A. K. Skidmore, S. Panitchart, T. Vaiphasa, N. Bamrongrugsa, P. Santitamnont, 2007, Impacts of Shrimp Pond Waste Materials on Mangrove Growth and Mortality: A Case Study from Pak Phanang, Thailand, Hydrobiologia 591:47 57 
Delvian. et al. Pertumbuhan Rhizophora Stylosa Pada Tambak Silvofishery di Desa Tanjung Rejo ...

Walters, B.B., P. Ronnback, J.M. Kovacs, B. Crona, S.A. Hussain, R. Badola, J.H. Primavera, E. Barbier, F. Dahdouh Guebas,
2008, Ethnobiology, Socio-Economics and Management of Mangrove Forests: A review, Aquatic Botany 89: 220 - 236 